\title{
Development and Application Effects of Nursing Simulation Program for Pneumonia Care Training Using Premature Anne
}

\author{
Nayoung Choi $^{1}$ \\ ${ }^{1}$ Associate Professor, Department of Nursing Science, Andong National University, Republic of \\ Korea, choice4na@hanmail.net
}

Corresponding author: Nayoung Choi

\begin{abstract}
This study aimed to develop a nursing simulation-based education for pneumonia using a Premature Anne. After explaining the program in detail and receiving documents of consent from nursing students, the control group received lecture-based education while the experimental group received both the lectures and the simulation-based training. Both groups were then tested for the effect on their academic motivation, clinical skills and knowledge. The collected data were analyzed using the statistical program SPSS WIN 24.0. In addition, the subjects' homogeneity were calculated, along with the hypotheses analyzed via t-tests. It was observed that before the education program, subjects that underwent the simulation training had a statistically significant difference in academic motivation scores $(\mathrm{t}=3.350, \mathrm{p}<.001)$, clinical skills $(\mathrm{t}=5.859, \mathrm{p}<.001)$. Therefore, this study was significant for it has identified that the use of a nursing simulation program for pneumonia and Premature Anne showed a positive increase in academic motivation and clinical skills. This study also suggests an efficient method in education for pneumonia care training.
\end{abstract}

Keywords: Simulation, Program, Pneumonia, Premature

\subsection{Background}

\section{Introduction}

Traditionally, education in universities has been centered around lectures for some time[1]. Although lecture-based education is very effective in communicating knowledge, there is a limit to increasing nursing ability in a clinical setting[2]. Therefore, developing an effective nursing clinical skill education program to supplement the lectures is an urgent matter.

Due to the fact that mistakes are not permitted in a real hospital and clinic environment, nursing students experience anxiety and fear over dealing with real patients in clinical practice. Most of this fear stems from the students not being familiar with the environment, advanced technology and equipment, the patients' family, hospital and nursing staff and thus tend to make mistakes here and there.

In order to complement these mistakes that nursing students make, there has recently been an interest from the clinical community to develop a simulation-based training program in the most up-to-date hospital environment while protecting the patients' rights and health[3].

A simple mannequin that provides a similar scenario to a hospital and aims at providing simulation education is one example. There is also a computer simulator, a High-fidelity Patient Simulator (HPS),

Received: October 06, 2020; 1st Review Result: November 24, 2020; 2nd Review Result: January 12, 2021 Accepted: February 26, 2021 
a Standardized Patient (SP), simulation games among other simulation-based education methods that provide the most similar simulation scenarios while providing nursing students with the opportunity to apply clinical skills and knowledge directly[4].

The Premature Anne is a a computer simulator and a High-fidelity Patient Simulator (HPS) made by the American Academy of Pediatrics (AAP). And the Premature Anne is a 25 week old premature baby's body[5].

Premature babies include newborn babies who have had a gestational period of less than 37 weeks. Note that the premature baby birth rate of a country can serve as an indicator of that country's healthcare, society and economic status[6]. Premature babies have physiologically less developed lungs and so their protective mechanisms against infections are lacking in general. Therefore, premature babies are more likely to be hospitalized, use mechanical ventilation, enter the Intensive Care Unit (ICU), and face death than normal children[7]. But researches done with a premature babies were very difficult and rare. Therefore, there is a need for research that deals with various methods to nurse premature babies that may face many severe aftereffects and issues.

In several previous studies on simulation-based training for clinical nursing education, scenarios similar to actual clinical situations are used on a standardized patient in order to understand the effect of students' practical skill knowledge and improve decision-making abilities[8]. Another study utilized simulation-based training and debriefing in order to understand the effect of knowledge acquisition, clinical skill application and academic effect among other studies[9].

However, most of the previous studies dealt with adult patients, nursing fundamentals and maternal nursing. There are limited studies on simulation-based training for child nursing simulations[10]. Simulation-based training on child nursing could be an effective method to train and test the clinical skills and safe decision-making abilities of nursing students who have yet to experience various experiences of nursing expertise even within a limited hospital ward[11]. Therefore, there is a need for research that focuses on simulation-based nursing training on various subjects and via methods within the field of child nursing even when performed in a limited clinical ward.

This study aimed to develop and apply a simulation-based nursing training program using Premature Anne to simulate a scenario with a premature child patient suffering from pneumonia. The study intended to verify the effect on the subjects' academic motivation, clinical nursing skills and knowledge before and after the simulation-based clinical training. Also, it aimed to provide practical foundational data on simulation-based nursing education.

\subsection{Purpose of Study}

This study aimed to develop a simulation-based nursing training on premature babies with pneumonia using a Premature Anne, and compares the difference of academic motivation, clinical nursing skills and knowledge compared to traditional education before and after the simulation program.

\subsection{Hypothesis}

\subsubsection{Hypothesis 1}

The experimental group who received the simulation-based training on nursing premature babies with pneumonia would have a higher academic motivation score than the control group.

\subsubsection{Hypothesis 2}

The experimental group who received the simulation-based training on nursing premature babies with pneumonia would have a higher clinical practical ability score than the control group. 


\subsubsection{Hypothesis 3}

The experimental group who received the simulation-based training on nursing premature babies with pneumonia would have a higher knowledge score than the control group.

\subsection{Definition of Terms}

\subsubsection{Simulation Program}

A simulation program is an education program using a simulator to reenact a clinical situation artificially using a mechanical device[12]. In this study, researcher makes a program of simulation scenario using a Premature Anne where a premature baby patient is brought into the ICU for newborns and the simulation aims to test the students' ability to grasp the situation and mediate and treat the patient properly.

\subsubsection{Premature Anne}

The Premature Anne refers to the mannequin developed by the American Academy of Pediatrics (AAP) that is very similar in size to a 25 week old premature baby's body proportions and has the heart, lungs, voice and cyanosis of a premature child[5]. The Premature Anne is used by medical professionals in order to aid in education and acquisition of nursing skills and recovery skills in clinical simulation scenarios[5].

\section{Research Method}

The study's general research process were divided into the representative professor system design model called the Analysis, Design, Development, Implementation, Evaluation (ADDIE) with 5 parts[13].

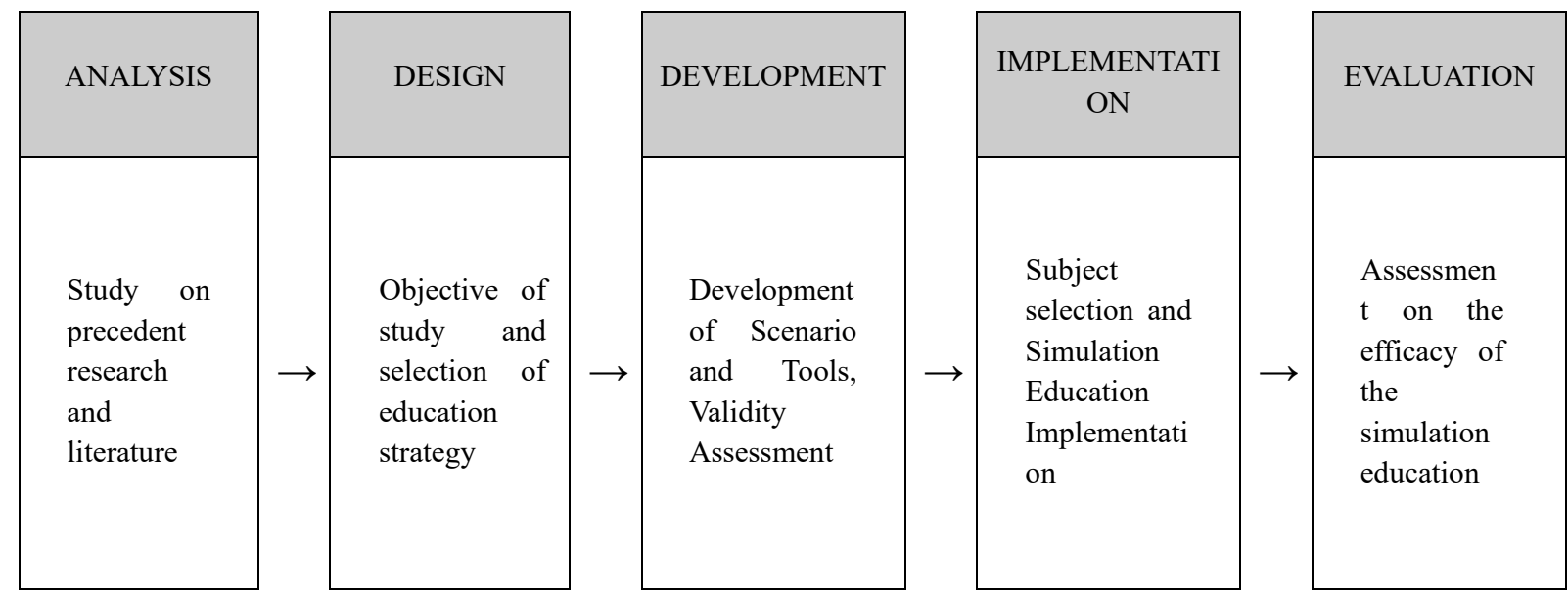

[Fig. 1] Research Process according to ADDIE Model

\subsection{Analysis}

Data were collected on the required scenarios and education process required for a proper nursing scenario on premature child patient nursing. Analysis on the contemporary and precedent research literature was done via searching for the keywords premature nursing, pneumonia patient nursing, simulation education on the RISS, PubMed websites and after careful research and analysis, a nursing simulation scenario was selected. 


\subsection{Research Design}

This study was a non-equivalent control group pretest-posttest design[Table 1] aimed to develop a nursing simulation scenario on premature children patients and compare the academic motivation, clinical skills and knowledge before and after a lecture-based program is given to the control group and a simulation-based training is given to the experimental group.

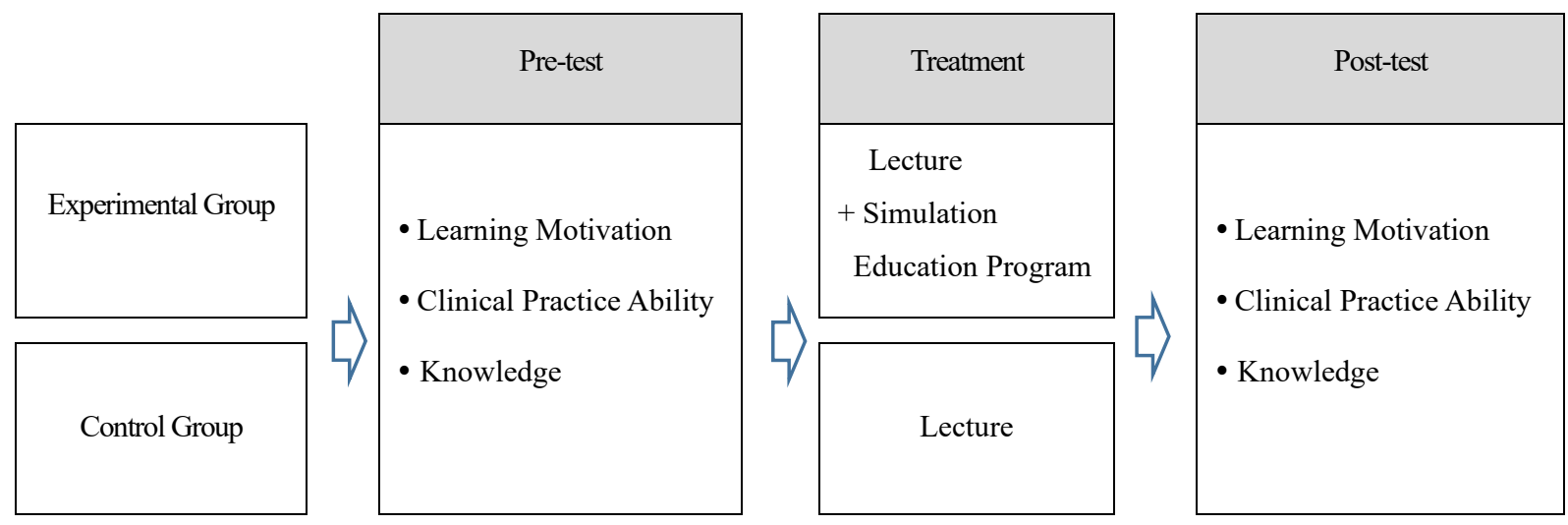

[Fig. 1] The Flow of Research

[Table 1] Research design

\begin{tabular}{|c|c|c|c|}
\hline & Pre-test & Treatment & Post-test \\
\hline Exp. $(\mathrm{N}=24)$ & \multirow{2}{*}{$\begin{array}{ll}\text { - } & \mathrm{L}_{1} \\
\text { - } & \mathrm{C}_{1} \\
\text { - } & \mathrm{K}_{1}\end{array}$} & $X_{1}+X_{2}$ & \multirow{2}{*}{$\begin{array}{ll}\text { - } & \mathrm{L}_{2} \\
\text { - } & \mathrm{C}_{2} \\
\text { - } & \mathrm{K}_{2}\end{array}$} \\
\hline Cont. $(\mathrm{N}=25)$ & & $\mathrm{X}_{1}$ & \\
\hline
\end{tabular}

Exp.= Experimental group Cont.= Control group

$\mathrm{L}_{1}, \mathrm{~L}_{2}=$ Learning Motivation, $\mathrm{C}_{1}, \mathrm{C}_{2}=$ Clinical Practice Ability, $\mathrm{K}_{1}, \mathrm{~K}_{2}=$ Knowledge

$\mathrm{X}_{1}=$ Lecture, $\mathrm{X}_{2}=$ Simulation Education Program

\subsection{Development of Program}

A detailed education program was developed for "Nursing a Premature baby with Pneumonia" in order to increase academic motivation, clinical practical ability, knowledge and tools. A simulation scenario was introduced in order to reflect the needs of such a program.

\subsubsection{Development of Tool}

\section{1) Learning Motivation}

For the questions regarding academic motivation, the questions were repurposed from Mi Young Shin's study(2013)[14]. The questions' content validity were verified by 3 nursing professors and a total of 14 questions were repurposed for the study. Only items which took a Content Validity Index (CVI) score of at least 0.80 developed it to the questionnaire. Each question's answer ranged from a 1 indicating 'Not at all', to 5 indicating 'Almost always' as a Likert scale with a higher score indicating 
higher academic motivation. This study's academic motivation Cronbach's $\alpha$ was 0.87 .

\section{2) Clinical Practical Ability}

The questions for clinical practical ability was adopted and modified from Yun Hee Kim's study(2010) [2] and verified by 3 nursing professors for its content validity. A total of 23 questions were used and each question's answer had a range from 1 to 5 based on the Likert scale. A higher score indicating a higher self-efficacy. This study's clinical practical ability had a Cronbach's $\alpha$ of 0.90 .

\section{3) Knowledge}

For knowledge, child nursing academic materials were referenced to create questions and 3 separate nursing professors verified the content validity of the questions. This field included 20 questions and the Cronbach's $\alpha$ for this field was 0.85 .

\subsubsection{Development of Simulation Scenario}

This study developed a simulation scenario based on child nursing academic materials and received validity confirmation from 3 child nursing professors and 1 pediatrician in the process. The aforementioned experts modified and complemented the simulation scenario as they saw fit. The preliminary experiment was run on 5 students for intervals of 15 minutes of clinical nursing and 10 minutes of debriefing.

This study utilized a clinical scenario in which a 25 week old premature baby born through a Caesarean Section surgery has entered the Newborn Intensive Care Unit (NICU) 5 days ago and has received a pneumonia diagnosis 2 days prior. The premature baby patient requires intensive nursing care and a planned nursing intervention process is carefully required in such a scenario.

\subsection{Implementation}

\subsubsection{Sampling of Research Subject}

This study was conducted on nursing students in their 4th year at a university after careful explanation about the schedule and process and receiving signatures of consent from the subjects who;

1) was from 21 to 30 years old,

2) has not received simulation education training,

3) could communicate, understand the research and voluntarily agreed to it.

This study was first performed on 50 students and surveys that were filled out without effort or with omitted answers were left out of the final count. 24 students in the experimental group and 25 students in the control group were selected for a total sample of 49 students. There were 4 students per team in the simulation program.

\subsubsection{Research Procedure}

\section{1) Collection of Data}

The data of the study was collected between November 2th, 2019 to December 20th of the same year on 4thyear nursing major university students after a thorough explanation of the study and receiving signatures of consent. After receiving consent from the students, a brief orientation and survey questionnaire was given in order to collect prior data on academic motivation on premature babies with pneumonia, clinical nursing skills and knowledge. Then, a lecture-based education along with the simulation scenario on premature babies with pneumonia was given to the experimental group in order 
to measure the academic motivation, clinical practical skills and knowledge after the program.

\subsection{Evaluation}

The data collected in this study was analyzed using SPSS WIN 24.0. The general characteristics of the subjects along with the variables' frequency, percentages, mean and standard deviation were computed. The hypothesis on the two groups' general characteristics homogeneity, along with academic motivation, clinical skills and knowledge before and after were verified via t-tests. The degree of reliability was computed using Cronbach's $\alpha$.

\section{Result}

\subsection{General Characteristics of Subjects}

Before running the premature baby nursing simulation-based training program using the Premature Anne, the general characteristics on the subjects were collected. The control and experimental groups' homogeneity, age, religion, academic performance before and after the study were analyzed and as a result, no significant difference ( $\mathrm{p}>.05$ ) was found between the two groups[Table 2].

[Table 2] General Characteristics of Subjects $(\mathrm{N}=49)$

\begin{tabular}{|c|c|c|c|c|}
\hline Variables & Categories & $\begin{array}{l}\text { Experiment group } \\
\qquad \begin{array}{c}(\mathrm{n}=24) \\
\mathrm{n}(\%)\end{array}\end{array}$ & $\begin{array}{l}\text { Control group } \\
\qquad \begin{array}{c}(\mathrm{n}=25) \\
\mathrm{n}(\%)\end{array}\end{array}$ & $\begin{array}{c}\text { Total } \\
(\mathrm{N}=49) \\
\mathrm{n}(\%)\end{array}$ \\
\hline \multirow{3}{*}{ Age(year) } & $\leq 23$ & $8(33.3)$ & $9(36.0)$ & $17(34.7)$ \\
\hline & $24 \sim 25$ & $12(50.0)$ & $14(56.0)$ & $26(53.1)$ \\
\hline & $\geq 26$ & $4(16.7)$ & $2(8.0)$ & $6(12.2)$ \\
\hline \multirow{3}{*}{$\begin{array}{l}\text { Economic } \\
\text { status }\end{array}$} & Upper & $5(20.8)$ & $6(24.0)$ & $11(22.4)$ \\
\hline & Middle & $16(66.7)$ & $15(60.0)$ & $31(63.3)$ \\
\hline & Lower & $3(12.5)$ & $4(16.0)$ & $7(14.3)$ \\
\hline \multirow{4}{*}{ Religion } & Buddhism & $3(12.5)$ & $5(20.0)$ & $8(16.3)$ \\
\hline & Christians & $9(37.5)$ & $7(28.0)$ & $16(32.7)$ \\
\hline & Catholicism & $7(29.2)$ & $8(32.0)$ & $15(30.6)$ \\
\hline & Other or None & $5(20.8)$ & $5(20.0)$ & $10(20.4)$ \\
\hline \multirow{3}{*}{$\begin{array}{l}\text { Academic } \\
\text { records before } \\
\text { semester }\end{array}$} & $\leq 2.9$ & $2(8.3)$ & $1(4.0)$ & $3(6.1)$ \\
\hline & $3.0 \sim 3.9$ & $18(75.0)$ & $19(76.0)$ & $37(75.5)$ \\
\hline & $\geq 4.0$ & $4(16.7)$ & $5(20.0)$ & $9(18.4)$ \\
\hline
\end{tabular}




\subsection{Test of Hypothesis}

\subsubsection{Hypothesis 1}

In order to confirm Hypothesis 1 that "The experimental group who received the simulation-based training on nursing premature babies with pneumonia would have a higher academic motivation score than the control group", the academic motivation scores between the control and experimental group were compared. It was observed that the experimental group had an average academic motivation score of 48.44( $( \pm 10.03)$ which was seen as significantly higher $(t=3.350, p<.001)$ than the control group's score of 40.92( \pm 5.32$)$, and thus, Hypothesis 1 was supported in this study[Table 3].

\subsubsection{Hypothesis 2}

In order to confirm Hypothesis 2 that "The experimental group who received the simulation-based training on nursing premature babies with pneumonia would have a higher clinical practical ability score than the control group", the clinical practical ability scores between the two groups were compared. It was observed that the experimental group had a significantly higher $(\mathrm{t}=5.859, \mathrm{p}<.001)$ clinical practical ability score of $88.40(( \pm 12.73)$ as opposed to the control group's score of $70.95( \pm 7.10)$ and thus, Hypothesis 2 was supported in this study[Table 3].

\subsubsection{Hypothesis 3}

In order to confirm Hypothesis 3 that "The experimental group who received the simulation-based training on nursing premature babies with pneumonia would have a higher knowledge score than the control group", the knowledge scores of the control and experimental group were compared. It was observed that the experimental group did not have a significantly higher $(\mathrm{t}=1.12, \mathrm{p}=.134)$ knowledge score at $12.38( \pm 2.43)$ than the control group's score of $11.46( \pm 3.36)$, and thus, Hypothesis 3 was rejected in this case[Table 3].

[Table 3] Comparison on Learning Motivation, Clinical Practice Ability and Knowledge ( $\mathrm{N}=49)$

\begin{tabular}{|c|c|c|c|}
\hline Variables & Learning Motivation & Clinical Practice Ability & Knowledge \\
\hline $\begin{array}{c}\text { Exp. }(N=24) \\
\mathrm{M} \pm \mathrm{SD}\end{array}$ & $48.44 \pm 10.03$ & $88.40 \pm 12.73$ & $12.38 \pm 2.43$ \\
\hline $\begin{array}{c}\text { Cont. }(N=25) \\
\mathrm{M} \pm \mathrm{SD}\end{array}$ & $40.92 \pm 5.32$ & $70.95 \pm 7.10$ & $11.46 \pm 3.36$ \\
\hline $\mathrm{t}$ & 3.350 & 5.859 & $<.001^{*}$ \\
\hline$p$ & $<.001^{*}$ & 1.120 & .134 \\
\hline
\end{tabular}




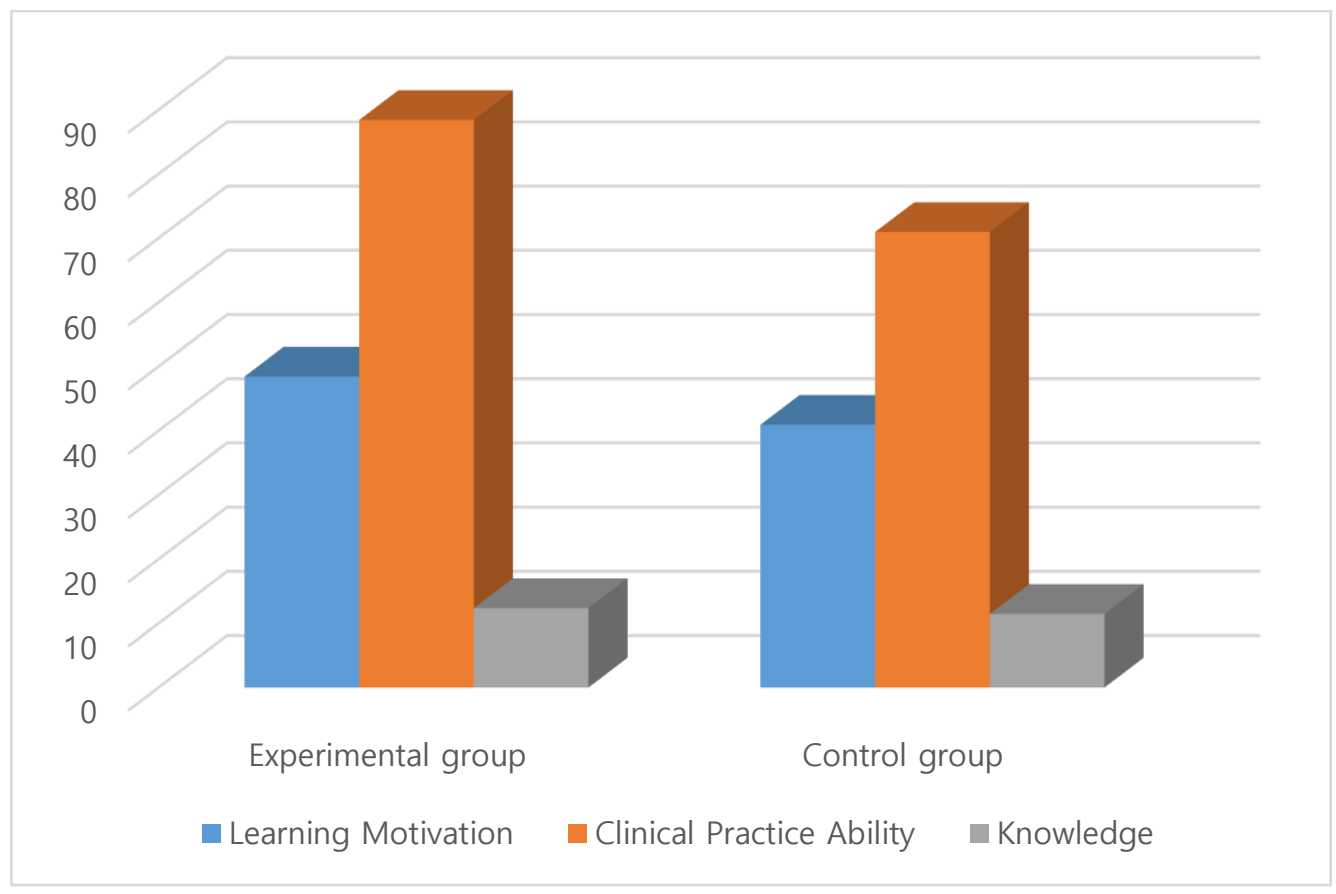

[Fig. 2] Comparison on Learning Motivation, Clinical Practice Ability and Knowledge

\section{Discussion}

This study developed a nursing simulation education program for premature babies with pneumonia and tested it on students to understand and compare its effects on academic motivation, clinical practical ability and knowledge. The study aimed to provide a foundation for nursing education based on simulation in the future.

This study showed that a nursing simulation education program based on premature babies with pneumonia significantly increased the students' academic motivation scores $(t=3.350, p<.001)$. Academic motivation has a positive effect on the students' attitude towards studying and their academic efficiency and it plays an important role in the students' academic studies[15]. In addition, it has been shown in several studies academic motivation exercises a positive effect on academic achievement and its importance in an academic setting is being emphasized as of late[16]. Therefore, the fact that the nursing simulation-based training showed a positive and significant increase in academic motivation shows that the program is effective and that the program can exert a positive influence on academic achievement in students.

In addition, the study demonstrated that the nursing simulation program had a positive effect on the subjects' clinical practical ability $(\mathrm{t}=5.859, \mathrm{p}<.001)$. The results of this study were consistent with Jin Ju Yang's study(2008)[17] in which university nursing major students in an experimental group who went through a simulation-based training showed higher clinical practical ability than the control group students who only received theory-based lectures.

On the other hand, the results of Jeong Suk Kim's study(2012)[18] indicated that there wasn't a significant difference in clinical practical ability between students in a control group who received theory-based lecture and an experimental group who received theory-based lecture and simulation-based training. However, note that this may be due to the fact that the experimental group received the simulation training after a series of lectures and clinical practice or that the simulation-based training was too short. Nevertheless, this study demonstrated that simulation-based training can be a means towards increasing the clinical practical ability of students. More research is required in order to 
understand the content of simulation training, the time period of simulations and other scenarios for future use by nursing educators.

In this study, a significant difference in knowledge was not observed between the control and experimental group $(\mathrm{t}=1.12, \mathrm{p}=.134)$. This result was not consistent with Brannam et al.'s study (2008)[19] which showed that subjects who received simulation-based training had a higher knowledge score than those who received traditional lecture-based education. However, based on Keum Suk Kim's study (2001)[20] which demonstrated that a 3 week simulation-based training on subjects allowed for a significant difference in knowledge scores over subjects who received traditional lectures, it can be assumed that a longer period of simulation-based training may be required.

The results of this research could not be generalized because it was carried out within a nursing course at one single school, and convenience sampling technique was used.

\section{Conclusion}

This study played a significant role in showing that a simulation-based nursing training program on premature babies with pneumonia can have a positive effect on students' academic motivation and clinical practical ability. In addition, this study showed the promising potential of a simulation-based education program for nursing students.

More research is required in order to understand simulation-based training programs in various fields of nursing, its positive and negative effects, and the different methods and time periods that may be applied for the near future.

\section{References}

[1] G. M. Lee, Preliminary Study for the Development of In-Service Education Course for ICU Nurses according to their Career Stage, Sungkyunkwan University, Master's thesis, (2004)

[2] Y. H. Kim, Effect of a Simulation-based Education on Cardio-pulmonary Emergency Care Knowledge, Clinical Performance Ability and Problem Solving Process Among New Nurses, Chonnam National University, Doctor Dissertation, (2010)

[3] PAMELA R. JEFFRIES, A Framework Designing, Implementing, and Evaluating: Simulations Uesd as Teaching Strategies in Nursing, Nursing Education Perspectives, (2005), Vol.26, No.2, pp.96-103.

[4] S. O. Lee, M. R. Eom, J. H. Lee, Use of Simulation in Nursing Education, The Journal of Korean Academic Society of Nursing Education, (2007), Vol.13, No.1, pp.90-94,

[5] https://www.laerdal.com/kr/item/295-00050, Jun 4 (2020)

[6] Y. J. Han, K. Seo, H. C. Oh, S. M. Shin, J. S. Hong, J. S. Choi, N. H. Lee, A Study on the Estimation of Low-birth Weight, Korea Institute for Health and Social Affairs, (2007), pp.88-92.

[7] B. J. Law, X. Carbonell-Estrany, E.A.F. Simões, An Update Respiratory Syncytial Virus Epidemiology:A Developed Country Perspective, Respiratory Medicine, (2002), Vol.96, Supp 2, pp.S1-S7, https://doi.org/10.1053/rmed.2002.1294

[8] M. S. Lee, S. W. Han, Effect of Simulation-based Practice on Clinical Performance and Problem Solving Process for Nursing Students, The Journal of Korean Academic Society of Nursing Education, (2011), Vol.17, No.2, pp.226-234, https://doi.org/10.5977/JKASNE.2011.17.2.226

[9] J. M. Lusk, K. Fater, Postsimulation Debriefing to Maximize Clinical Judgment Development, Nursing Educator, (2013), Vol.38, No.1, pp.16-19, DOI: 10.1097/NNE.0b013e318276df8b

[10] D. H. Kim, Y. J. Lee, M. S. Hwang, J. H. Park, H. S. Kim, H. K. Cha, Effects of a Simulation-based Integrated Clinical Practice Program(SICPP) on the Problem Solving Process, Clinical Competence and Critical Thinking in a Nursing 
Student, The Journal of Korean Academic Society of Nursing Education, (2012), Vol.18, No.3, pp.499-509, DOI : 10.5977/jkasne.2012.18.3.499

[11] M. A. Harris, Simulation-Enhanced Pediatric Clinical Orientation, The Journal of Nursing Education, (2011), Vol.50, No.8, pp.461-465, https://doi.org/10.3928/01484834-20110429-05

[12] J. Cooper, V. Taqueti, A Brief History of the Development of Mannequin Simulators for Clinical Education and Training, Quality and Safety in Health Care, (2004), Vol.13, Suppl 1, pp.i11-i18, doi: 10.1136/qshc.2004.009886

[13] http://www.nwlink.com/ donclark/history_isd/addie.html, Jul 10 (2020)

[14] M. Y. Shin, Aspects of Motivation and Self-efficacy Depending on Academic Performances in TOEIC, The Jungang Journal of English Language and Literature, (2013), Vol.55, No.4, pp.303-330, DOI : 10.18853/jjell.2013.55.4.014

[15] S. M. Park, Intervention Effects of Intrinsic Motivation Enhancing Strategy Academic Efficacy and Learning Attitude, Daegu National University of Education, Master's thesis, (2008)

[16] M. H. Kim, J. H. Ha, The Effects of Academic Motivation, Study Skill on Academic Achievement, School Adjustment, The Korean Journal Child Education, (2008), Vol.17, No.2, pp.33-48, UCI : G704-001652.2008.17.2.007

[17] J. J. Yang, Development and Evaluation of a Simulation-based Education Course for Nursing Students, Journal of Korean Academy of Adult Nursing, (2008), Vol.20, No.4, pp,548-560.

[18] J. S. Kim, Development and Effect of High Fidelity Patient Simulation Education Program for Nursing Students, Catholic University, Doctor Dissertation, (2012)

[19] J. D. Brannan, A. White, J. L. Bezanson, Simulator Effects on Cognitive Skills and Confidence Levels, Journal of Nursing Education, (2008), Vol.47. No.11, pp.495-500, https://doi.org/10.3928/01484834-20081101-01

[20] G. S. Kim, Effect of Simulation-Applied Social Studies Classes on the Learning of Economics, Incheon University of Education, Master's thesis, (2001) 